\title{
Conduction system engagement by mid-septal leadless pacemaker in a patient with persistent iatrogenic atrioventricular block
}

\author{
Giusy Sirico ${ }^{1} \odot$, Massimo Mantica ${ }^{1}$, Domenico Sirico ${ }^{2}$, \\ Andrea Montisci ${ }^{3,4}$, Federica Calabrese ${ }^{5}$, Massimo Pala ${ }^{5}$, Daniele Malaspina ${ }^{5}$ \\ ${ }^{1}$ Department of Cardiac Electrophysiology and Pacing, Istituto Clinico Sant'Ambrogio, Milan, Italy \\ ${ }^{2}$ Pediatric and Congenital Cardiology Unit, Department of Woman and Child's Health, \\ University of Padova, Italy \\ ${ }^{3}$ Department of Anesthesia and Intensive Care, Istituto Clinico Sant'Ambrogio, Milan, Italy \\ ${ }^{4}$ Chair of Cardiac Surgery, Postgraduate in Cardiac Surgery, University of Milan, Italy \\ ${ }^{5}$ Department of Cardiology and Pacing, ASST Santi Paolo e Carlo, Milan, Italy
}

An 89-year-old woman was admitted to our Arrhythmology Unit for syncope. Electrocardiogram (ECG) showed sinus rhythm with left bundle branch block (LBBB) (Fig. 1A). Holter ECG monitoring showed paroxysmal atrial fibrillation with difficult rate control. The patient was referred for 'ablate and pace' strategy. Left subclavian vein occlusion prevented the traditional pacing implant. Micra $^{\mathrm{TM}}$ TPS was implanted in the right ventricle mid-septal position causing right bundle branch (RBB) bump and atrioventricular block that was promptly treated with a temporary pacing wire (Fig. 1B). Micra ${ }^{\mathrm{TM}}$ was successfully deployed (Fig. 1C,D). Pacing threshold was 0.50V @ 0.24 ms, sensing was $6.4 \mathrm{mV}$ and impedance was $610 \mathrm{Ohm}$. Pacemaker dependency was persistent. Paced QRS was identical in morphology and duration to baseline QRS: duration of $130 \mathrm{~ms}, \mathrm{rS}$ complex in inferior leads, positive $\mathrm{R}$ wave in lead $\mathrm{I}$ and $\mathrm{aVL}$ with a typical notch at the onset of QRS (Fig. 1E). Pacing at high output (5 Volt @ $1 \mathrm{~ms}$ ) did not change QRS morphology (Fig. 1F). There are two possible explanations of this phenomenon: 1) the different localizations between the site of RBB induced block and Micra ${ }^{\mathrm{TM}}$ pacing site, with potential selective activation of the right bundle; 2 ) the greater surface of endocardial contact of the Micra ${ }^{\mathrm{TM}}$ resulted in the capture of a greater portion of conduction tissue fibers connected downstream from the site of RBB block. The ability of Micra ${ }^{\mathrm{TM}}$ leadless pacemakers to selectively pace the conduction system could allow remarkable advantages in terms of QRS duration.

Conflict of interest: None declared

Address for correspondence: Giusy Sirico, MD, PhD, Via L.G.Faravelli n.16, Istituto Clinico Sant'Ambrogio, 20149, Milan, Italy, e-mail: giusy.sirico@gmail.com

This article is available in open access under Creative Common Attribution-Non-Commercial-No Derivatives 4.0 International (CC BY-NC-ND 4.0) license, allowing to download articles and share them with others as long as they credit the authors and the publisher, but without permission to change them in any way or use them commercially. 

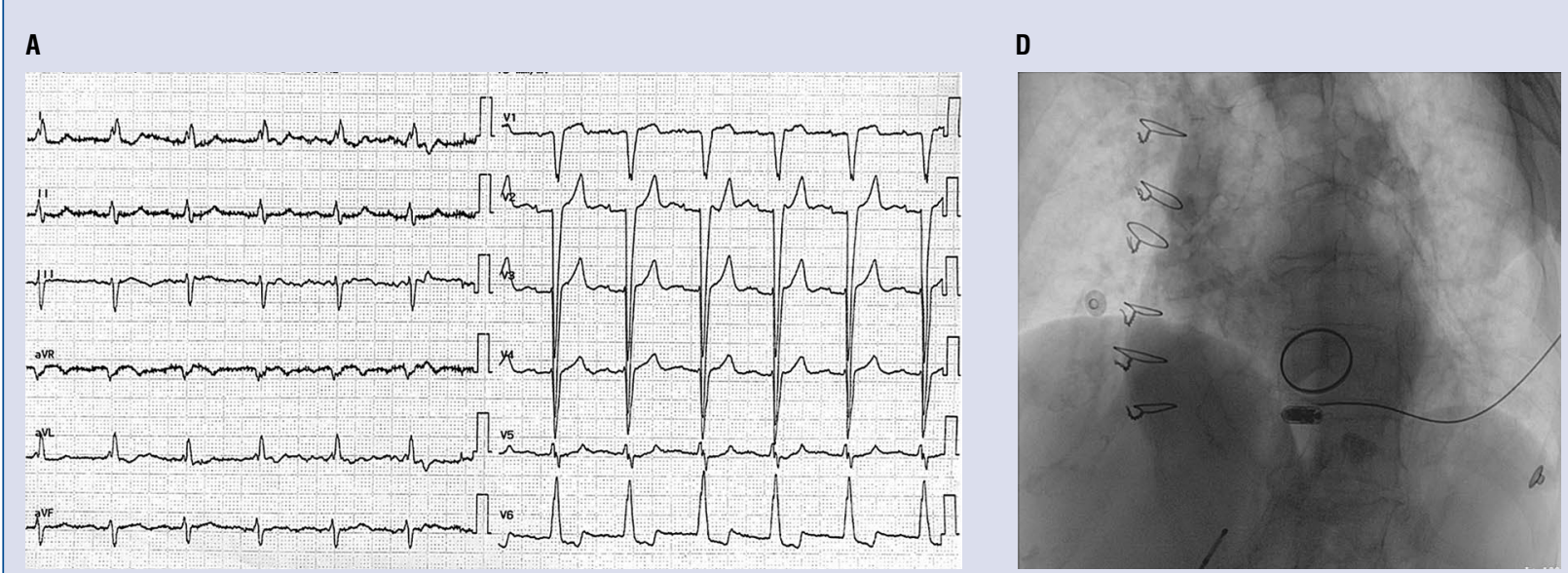

B

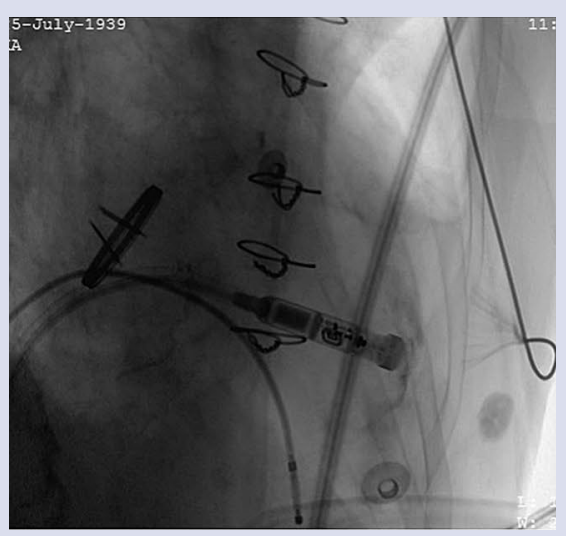

C

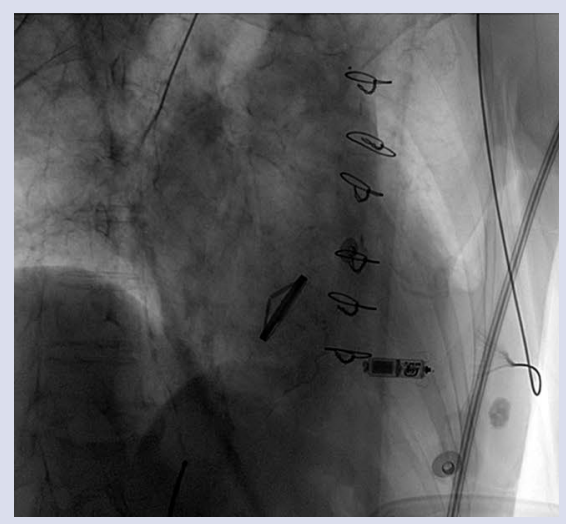

E

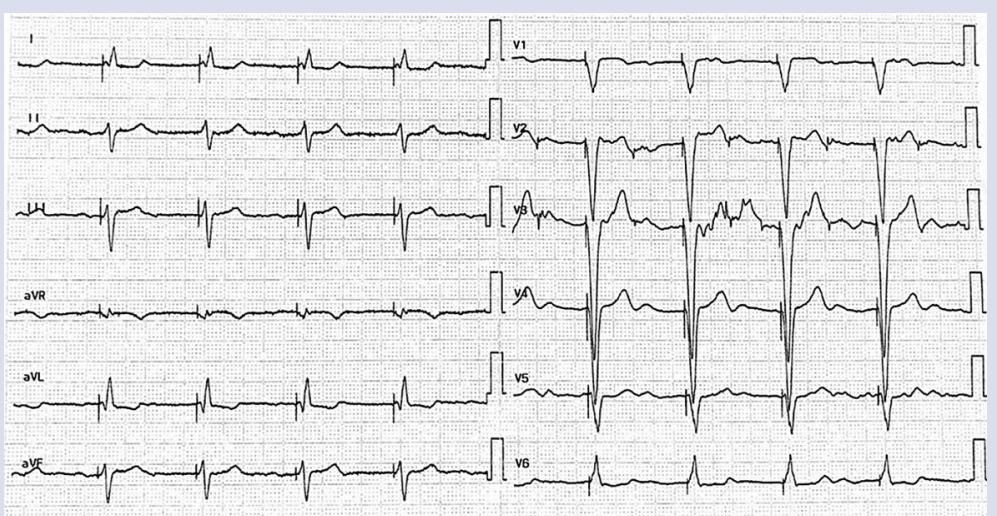

F

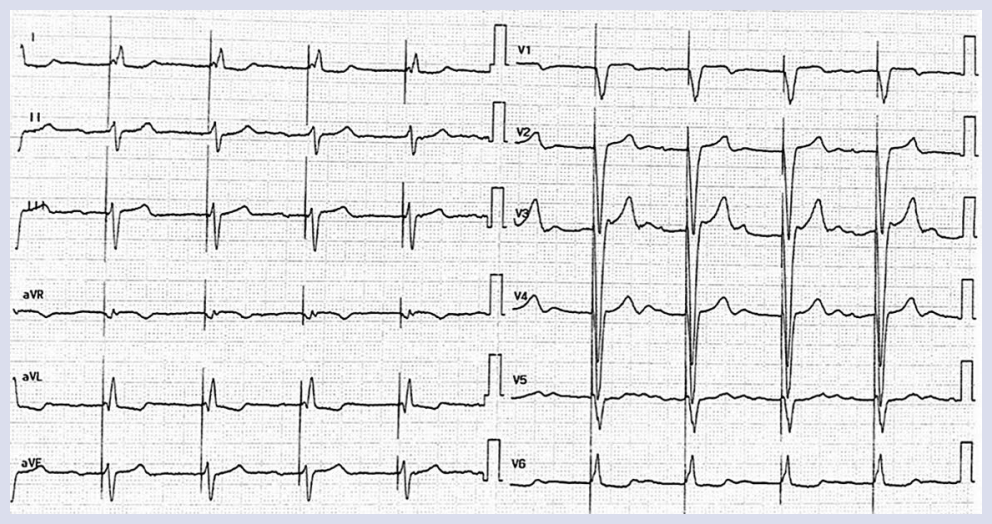

Figure 1. Micra ${ }^{\mathrm{TM}}$ implantation and paced electrocardiogram (ECG); A. Baseline 12 lead ECG at admission; B. Right anterior oblique view of Micra ${ }^{\mathrm{TM}}$ implantation and temporary pacing lead; C, D. Right and left anterior oblique view of Micra $^{\mathrm{TM}}$ system successfully deployed at right ventricle mid-septum; E. 12 lead ECG after Micra ${ }^{\mathrm{TM}}$ implantation with pacing at $2.5 \mathrm{~V} @ 0.4 \mathrm{~ms} ;$ F. 12 lead ECG with pacing at $5 \mathrm{~V} @ 1 \mathrm{~ms}$. The panels B, C and D show the mechanical valve 27 SJM Regent previously implanted in the mitral position. 